\title{
Platelet-rich Fibrin and its Application in Dentistry: An Institutional Experience
}

\author{
MD Tipu Sultan, Sandeep K. Pachisia, Rajarshi Banerjee, Sudipta Sahu, Abhinaba Bose \\ Department of Oral and Maxillofaial Surgery, Hidsar, Haldia, West Bengal
}

Email for correspondence: drsudiptosahu@gmail.com

\begin{abstract}
An autologous strong and flexible fibrin including enriched platelet which contains growth factors and cytokines is called platelet-rich fibrin (PRF). PRF can be made very simply and requires no artificial materials unlike plateletrich plasma. While PRF is remodelled and released in the tissue, this includes cell growth, vascularization, collagen synthesis, osteoblast differentiation, and an anti-inflammatory reaction. PRF can stimulate regeneration of bone and soft tissue. PRF is used in the preservation of sockets, guided bone grafts, sinus lifts, dressing, and periodontal treatment.
\end{abstract}

Key words: Bone regeneration, dentistry, oral surgery, platelet-rich fibrin

\section{INTRODUCTION}

In recent times, a lot of research has been done regarding the use of platelet-rich fibrin (PRF) clot and PRF membrane. More research has been done on the use of PRF in oral surgery for bone augmentation, sinus lifts, and avulsion a sockets and in periodontics to correct intrabony defects (IBD), gingival recession, guided bone regeneration (GBR), and periapical lesions. It has also been used for regeneration in open apex, regenerative pulpotomies, and peri-apical surgeries.

PRF dwells among a new generation of platelet concentrate that jump-starts the healing process to maximize predictability. It consists of the platelets, cytokines, and the fibrin matrix. Platelets and leukocyte cytokines play an important part in the biology of this biomaterial, and degranulation of platelets entails the release of cytokines able to

\begin{tabular}{|l|l|}
\hline Quick Response Code & Article Info: \\
\hline doi: 10.5866/2017.9.10171 \\
\hline $\begin{array}{l}\text { Received: 04-08-2017 } \\
\text { Revised: 10-09-2017 } \\
\text { Accepted: 18-09-2017 } \\
\text { Available Online: 27-11-2017 (www.nacd. } \\
\text { in)(C NAD, 2017 - All rights reserved }\end{array}$ \\
\hline
\end{tabular}

stimulate cell migration and proliferation within the fibrin matrix, launching the first stages of healing. ${ }^{[1-3]}$ Fibrin matrix supporting them constitutes the determining element responsible for the real therapeutic potential of PRF. The biologic activity of the fibrin molecule highlights its significant cicatricial capacity. ${ }^{[2]}$ This biological role will help the understanding of clinical standpoint and therapeutic applications.

\section{Preparation of PRF}

PRF preparation was invented by Dr. Joseph Choukroun in 2000. It is the current technique authorized by the French Health Ministry in which $\mathrm{PRF}$ is prepared without using an anticoagulant during gelling. ${ }^{[4]}$ First, blood sample is collected from the patient without anticoagulant using a butterfly needle and $10 \mathrm{ml}$ blood collection tubes. Next, blood is immediately centrifuged on a tabletop centrifuge at a rate of $3000 \mathrm{rpm}$ for $10 \mathrm{~min}$ because as soon as it comes in contact with the glass surface begins to coagulate.

After centrifugation, the following 3 layers are obtained in the test tube [Figure 1]:

a) Topmost layer consisting of acellular plasma-poor protein( $\mathrm{PPP})$

b) PRF clot in the middle

c) $\mathrm{RBCs}$ at the bottom of the test tube. 


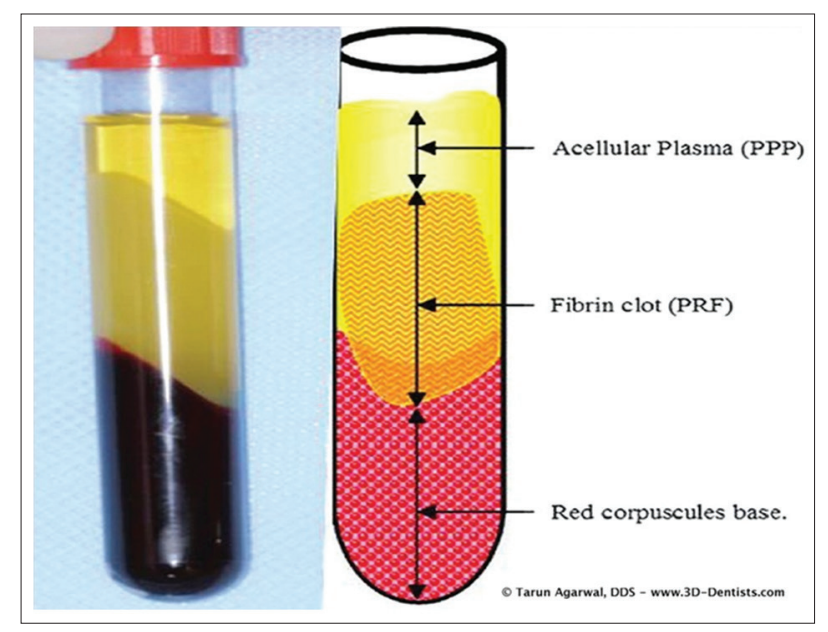

Figure 1: The constituent of the centrifuged blood

PRF clot is removed with a sterile tweezers and separated from the underlying RBC layer using scissors and then transferred on a sterile dish and stored in a refrigerator.

It is supposed that the junction of PRF to the $\mathrm{RBC}$ layer is rich in growth factors, and therefore, this region is preserved. ${ }^{[5]} \mathrm{PRF}$ results from a natural and progressive polymerization which occurs during centrifugation. PRF membrane can be obtained by squeezing out the liquids present in the fibrin clot. Liquid removal from the PRF fraction can be done through mechanical pressure between gauze layers, resulting in a fairly solid, gel-like material that can be used in various clinical applications as filling material or suturing membrane. ${ }^{[6]} \mathrm{PRF}$ membrane can also be prepared by compressing PRF clot in special tools like "PRF Box" resulting in standardized membranes of constant thickness and size along with PRF exudate. PRF exudates contain good amount of growth factors (transforming growth factor (TGF)- $\beta 1$, platelet-derived growth factor (PDGF)- $\beta$, and vascular endothelial growth factor (VEGF)), matrix glycoprotein's (fibronectin and vitronectin), and proteins specialized in increasing cell attachment to biomaterial impregnation, rinsing surgical sites, hydration of graft materials, and for storage of autologous grafts. ${ }^{[2,7,8]}$

Advantages of PRF over PRP are as follows:

- Simple and cost-effective method of preparation of PRF.

- Eliminates the use of bovine thrombin and thereby reduces the chances of cross infection.
- Slow natural polymerization of PRF on contact with glass particles of the test tube results in physiologic thrombin concentration, while in PRF sudden fibrin polymerization. ${ }^{[9]}$

- Fine and flexible 3D structure of PRF more favorable to cytokine enmeshment and cellular migration.

- PRF has supportive effect on immune system. ${ }^{[10]}$

- PRF helps in hemostasis.

- PRF is superior to PRP showed in vitro study, considering the expression of alkaline phosphatase and induction of mineralization, caused markedly by the release of TGF- $\beta 1$ and PDGF- $\beta$. ${ }^{[11]}$

\section{Function of growth factors}

\begin{tabular}{|c|c|}
\hline $\begin{array}{l}\text { Cytokines } \\
\text { present in } \\
\text { PRF }\end{array}$ & Functions \\
\hline TGF- $\beta$ & $\begin{array}{l}\text { (i) Released from } \beta \text {-granules of platelets } \\
\text { (ii) Stimulates proliferation of } \\
\text { osteoblasts }^{[4]} \\
\text { (iii) Synthesis of collagen type I and } \\
\text { fibronectin } \\
\text { (iv) Enhanced woven bone formation } \\
\text { (v) Enhanced chemotaxis of osteoblast } \\
\text { cells } \\
\text { (vi) Stimulates angiogenesis }\end{array}$ \\
\hline PDGF & $\begin{array}{l}\text { (i) Migration and proliferation of } \\
\text { mesenchymal lineage cells }{ }^{[5]} \\
\text { (ii) Angiogenic effect on endothelial cells }{ }^{[7]}\end{array}$ \\
\hline VEGF & (i) Initiates angiogenesis ${ }^{[2]}$ \\
\hline IGF-1 & $\begin{array}{l}\text { (i) Stimulates osteoblast proliferation }{ }^{[7]} \\
\text { (ii) Chemotactic effects toward human } \\
\text { osteoblasts } \\
\text { (iii) Increased expression of osteocalcin } \\
\text { (iv) Enhances wound healing }\end{array}$ \\
\hline FGF & $\begin{array}{l}\text { (i) Stimulates osteoblast proliferation }{ }^{[7]} \\
\text { (ii) Chemotactic effects toward human } \\
\text { osteoblasts } \\
\text { (iii) Increased expression of osteocalcin } \\
\text { (iv) Enhances wound healing }\end{array}$ \\
\hline EGF & $\begin{array}{l}\text { (i) Stimulation of cell proliferation and } \\
\text { extracellular matrix turnover }{ }^{[8]} \\
\text { (ii) Chemotactic effect on periodontal } \\
\text { fibroblast cell }\end{array}$ \\
\hline
\end{tabular}

PRF: Platelet-rich fibrin, TGF- $\beta$ : Transforming growth factor- $\beta$, PDGF: Platelet-derived growth factor, VEGF: Vascular endothelial growth factor, IGF-1: Insulin growth factor-1, FGF: Fibroblast growth factor, EGF: Epidermal growth factor 


\section{In oral and maxillofacial surgery}

\section{Use in extraction socket}

PRF will act as a stable blood clot for neovascularization and accelerated tissue regeneration. It also improves wound healing in immunocompromised and diabetic patients. ${ }^{[6]}$ PRF can stimulate coagulation (with thrombospondin) and wound closure, and thus, it is an adjuvant in patients on anticoagulant therapy. ${ }^{[12]}$

When bony walls are intact, PRF leads to very favorable results. Where one or several walls are missing or damaged, a combination of PRF with bone substitutes is used for adequate reconstruction of bone volume. $\mathrm{PRF}$ increases the cohesion between the graft materials as fibrin acts as physiological glue between the wound tissues. ${ }^{[12]}$ In cases of wide sockets and lesions where primary closure is difficult, PRF membrane can be used as a covering and protective membrane that promotes reepithelialization of the site and accelerates the merging of the wound margins.

The elasticity and strength of PRF fibrin membrane make it easy to suture. As a membrane for GBR, the PRF dense matrix architecture covers, protects, and stabilizes bone graft material and operative site in general.

\section{Sinus lift procedure}

PRF widely used as sinus lift procedures. Some studies show the use of PRF as the sole filling material during sinus lift and implantation. Some other studies show the use of PRF in combination with other bone graft materials in various direct and indirect sinus lift techniques such as boneadded sinus floor elevation, osteotome-mediated sinus floor elevation, and minimally invasive antral membrane ballon elevation. ${ }^{[1]}$

Some studies also show the use of PRF in combination with beta-tricalcium phosphate (beta TCP) without bone graft in sinus lift procedures.

\section{In periodontics}

$\mathrm{PRF}$ has been used to treat gingival recession, IBD, and periapical lesions. Some case reports show the use of a combination of PRF gel, hydroxyapatite graft, and guided tissue regeneration membrane to treat IBD. Studies show the use of PRF gel and PRF membrane in combination with a bone graft for treating a tooth with a combined periodontic endodontic lesion. ${ }^{[13]}$
PRF can promote the healing of osseous defects by the following mechanisms. According to Chang et al., PRF promotes the expression of phosphorylated extracellular signal-regulated protein kinase (perk) and stimulates the production of osteoprotegerin (OPG) which in turn causes proliferation of osteoblasts. PRF also releases growth factors such as PDGF and TGF which promote periodontal regeneration.

\section{In endodontics}

PRF can be used as a scaffolding material in an infected necrotic immature tooth for pulpal regeneration and tooth revitalization. ${ }^{[14]}$ Some case reports show that the combination of PRF membrane as a matrix and MTA in apexification procedures prove to be an effective alternative for creating artificial end barriers and to induce faster periapical healing. The use of a membrane can prevent extrusion of material. ${ }^{[15]}$

- Use of PRF in regenerative pulpotomy procedures have also seen documented where coronal pulp is removed and PFF is placed, followed by sealing with MTA and GIC. ${ }^{[16]}$

- PRF has also been used to fill bony defect after periapical surgeries like root end resection, etc.

\section{Apexogenesis}

$\mathrm{PRF}$ is rich in growth factors, enhances cellular proliferation and differentiation, and acts as a matrix for tissue in growth. The success of the use of PRF for regeneration of open apex could be attributed to a study, conducted by Huang et al., in 2010, and they conducted that the PRF causes proliferation of human dental pulp cells and increased the protein expression of these dental pulp cells differentiate into odontoblasts like cells by upgrading OPG and ALP expression of odontoblastic differentiation. ${ }^{[17]}$

\section{In tissue engineering}

A study by Gassling et al. reported that PRF appears to be superior to collagen as a scaffold for human periosteal cells proliferation and PRF membrane can be used for in vitro cultivation of periosteal cells for bone tissue engineering. The clinical part of PRF in this tissue engineering needs further investigation. 


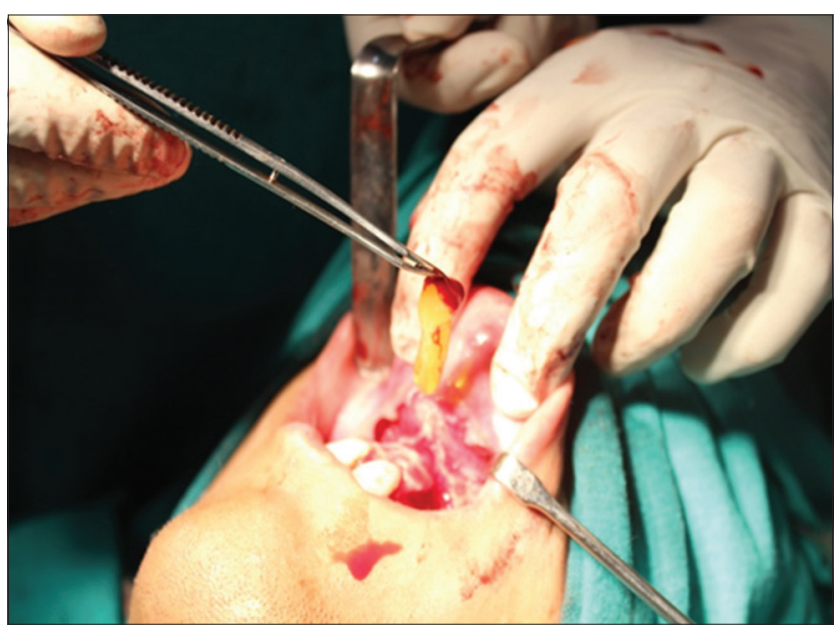

Figure 2: Platelet-rich fibrin after enucleation of cyst

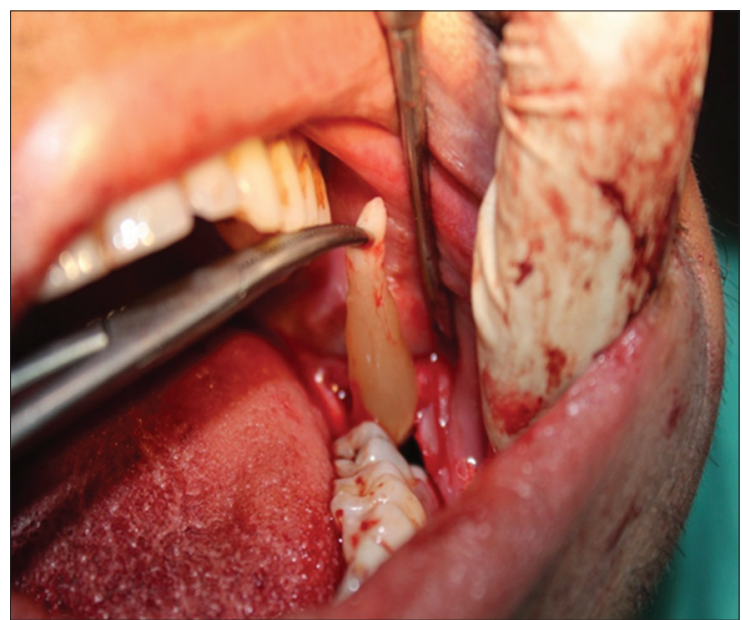

Figure 3: Platelet-rich fibrin in extracted third molar socket

\section{In facial plastic surgery ${ }^{[15,16]}$}

Application in,

- Facial volumization

- Nasolabial folds

- Acne scars

- Superficial rhytides

- Rhinoplasty

- Facial esthetic lipostructure

- Autologous fat transfer

- Rhytidectomy

- Depressed scar

- Dermal augmentation

\section{OUR EXPERIENCE IN PRF}

In our department of oral and maxillofacial surgery, we have been extensively using PRF in cases like cyst enucleation of small-to-medium sizes and also in implant and post-impaction sockets [Figures 2 and 3].

PRF causes osseoinduction of the bone, and post-operative results have yielded very good results compared with cases which are not given PRF. It is very simple to use and is cost effective also. Thus, $\mathrm{PRF}$ is a novel advancement in the field of oral and maxillofacial surgery as well as in other aspects of dentistry as well.

\section{CONCLUSION}

Thus, PRF can be successfully utilized in oral and maxillofacial area, it is biocompatible and can induce fundamental regeneration of bone and soft tissue.

PRF can produce an outstanding result in socket preservation surgery, alveolar and maxillary sinus bone graft, procedure to reduce inflammation around implants, and periodontal surgeries. If the more clinical study is carried out, PRF might itself a treatment of good prognosis. In recent reports, the effective treatments of skin and tendon wounds have been demonstrated. ${ }^{[17]}$ The clinical use of PRF will expand in dental treatments and other areas.

\section{REFERENCES}

1. Prakash S, Thakur A. Platelet concentrates: Past, present and future. J Maxillofac Oral Surg 2011;10:45-9.

2. Gupta V, Bains VK, Singh GP, Mathur A, Bains R Regenerative potential of platelet rich fibrin in dentistry: Literature review. Asian J Oral Health Allied Sci 2011;1:22-8.

3. Toffler M, Toscano N, Holtzclaw D, Del Corso M, Ehrenfest DD. Introducing Choukroun's platelet rich fibrin (PRF) to the reconstructive surgery milieu. J Implant Adv Clin Dent 2009;1:21-32.

4. Giannobile WV, Hernandez RA, Finkelman RD, Ryan S, Kiritsy CP, D'Andrea M, et al. Comparative effects of platelet-derived growth factor-BB and insulin-like growth factor-I, individually and in combination, on periodontal regeneration in Macaca fascicularis. J Periodontal Res 1996;31:301-12.

5. Lucarelli E, Beccheroni A, Donati D, Sangiorgi L, Cenacchi A, Del Vento AM, et al. Platelet-derived growth factors enhance proliferation of human stromal stem cells. Biomaterials 2003;24:3095-100.

6. Li Q, Pan S, Dangaria SJ, Gopinathan G, Kolokythas A, $\mathrm{Chu} \mathrm{S}$, et al. Platelet Rich fibrin promotesm periodontal regeneration and enhances alveolar bone augmentation. Biomed Res Int 2013;2013: Article ID: 638043, 13.

7. Raja VS, Naidu EM. Platelet-rich fibrin: Evolution of a second-generation platelet concentrate. Indian J Dent Res 2008;19:42-6. 
8. Moulin V. Growth factors in skin wound healing. Eur J Cell Biol 1995;68:1-7.

9. Chandran P, Sivadas A. Platelet-rich fibrin: Its role in periodontal regeneration. King Saudi Univ J Dent Sci 2013;29:287-91.

10. Malathi K, Muthukumaraswamy A, Beri S. Periodontal regeneration of an intrabony osseous defect with combination of platelet rich fibrin and bovine derived demineralized bone matrix: A case report. IOSR J Dent Med Sci 2013;4:20-6.

11. Singh S, Singh A, Singh S, Singh R. Application of PRF in surgical management of periapical lesions. Natl J Maxillofac Surg 2013;4:94-9.

12. Corso MD, Toffler M, David M, EhrenfestD. Use of autologous leukocyte and platelet rich fibrin (L-PRF) membrane in post avulsion sites: An overview of Choukroun's PRF. J Implant Adv Clin Dent 2010;1:27-35.

13. Naik B, Karunakar P, Jayadev M, Marshal VR. Role of
Platelet rich fibrin in wound healing: A critical review. $J$ Conserv Dent 2013;16:284-93.

14. Bajaj P, Rao NS, Agarwal E, Pradeep AR. Treatment of intrabony defect with platelet rich fibrin: A case report. Asian Oceanian Soc Radiol 2011;1:90-4.

15. Choukroun J, Diss A, Simonpieri A, Girard MO, Schoeffler C, Dohan SL, et al. Platelet-rich fibrin (PRF): A second-generation platelet concentrate. Part IV: Clinical effects on tissue healing. Oral Surg Oral Med Oral Pathol Oral Radiol Endod 2006;101:e56-60.

16. Lundquist R, Dziegiel MH, Agren MS. Bioactivity and stability of endogenous fibrogenic factors in platelet-rich fibrin. Wound Repair Regen 2008;16:356-63.

17. Simonpieri A, Del Corso M, Sammartino G, Ehrenfest DM The relevance of Choukroun's platelet-rich fibrin and metronidazole during complex maxillary rehabilitations using bone allograft. Part I: A new grafting protocol. Implant Dent 2009;18:102-11. 